\title{
Global governance and the Global Green New Deal: the G7's role
}

Injy Johnstone (iD) ${ }^{1 凶}$

Current headlines suggest that the world at large has missed the opportunity to 'build back better' from COVID-19 by way of a green recovery. However, such claims do not consider novel trends among plurilateral summit institutions, especially the extent to which global governance of a green recovery is encapsulated by the burgeoning norm bundle of the 'Global Green New Deal'. Plurilateral summit institutions like the G20, G7 and the BRICS have the potential to play a key governance role in implementing a Global Green New Deal, given the breadth and depth of reform required to 'build back better' from COVID-19. This contribution adopts a practice-relationist methodology to explore this thesis. Green recovery practice is analysed through novel interrogation of the open-source stimulus spending data of the Global Recovery Observatory. The results reveal that the G7, the G20 and the BRICS are all funding proportionally more clean than dirty stimulus in response to COVID-19. However, the proportion of clean stimulus is much stronger among members of the G7. A relationist frame is then used to assess this practice against the potential norm entrepreneurship role of the G7, both as individual member states and as a collective. It concludes that although this norm entrepreneurship role is undoubtedly nascent, it yields valuable insights into the pathways and barriers for further norm diffusion of the Global Green New Deal among plurilateral summit institutions. In this way it highlights the unique role plurilateral summit institutions can play in not only globalising the green new deal, but crucially operationalising it. Thus, while the world may not yet be 'building back better' as a collective, it is institutional norm entrepreneurs who currently hold the blueprints.

\footnotetext{
${ }^{1}$ Victoria University of Wellington, Wellington, New Zealand. ${ }_{\text {email: injy.johnstone@vuw.ac.nz }}$
} 


\section{Introduction}

- he Global Green New Deal (GGND) first emerged in response to the Global Financial Crisis (GFC). At its core it can be understood as an approach to both decarbonise and develop the economy, both through domestic and international coordination. Over the past decade, the GGND has begun to evolve from a policy package to a nascent norm bundle, which has seen diffusion and adaptation on a range of state and substate levels since its re-emergence in 2019. In 2020, the GGND's normative development was further accelerated by calls to 'build back better' from COVID-19 by way of a green recovery (Boyle et al., 2021: p. 8; O'Callaghan and Murdock, 2021). Despite the GGND's growing ubiquity in global affairs, it remains poorly understood as a conceptual phenomenon. This leads to the current consensus that the world failed to 'build back better' (O'Callaghan and Murdock, 2021: p. 40), without addressing on a more granular level the ways in which its processes may already be at play. To assess the GGND's evolution and impact on attempts to 'build back better', scholars must cast aside preconceptions and freshly consider the contemporary role it could play in international relations (IR). As the GGND shapes and is shaped by the conduct of an array of international actors, a global governance approach is best suited to investigate the GGND's normative potential. This contribution adopts a practicerelationist approach to identify emerging trends in the global governance of the GGND among plurilateral summit institutions (PSIs). In doing so, it seeks to contribute to burgeoning scholarship on the GGND (Boyle et al., 2021) and global governance post-COVID-19 (Larionova and Kirton, 2020).

Global governance approaches to IR reflect the increasing role 'global society' plays in norm creation (Barnett and Sikkink, 2011: p. 748). However, the popularity of global governance in academic literature has resulted in a measure of conceptual fuzziness (Hofferberth, 2016). As such, global governance is viewed as a policy notion, an empirical condition, and an analytical tool (Hofferberth, 2016). This communication adopts the twin approach of practice-relationism to explore each definition in turn. First, it outlines the GGND as a policy notion through exploring its normative inception and evolution. Second, the GGND is explored as an empirical condition reflected in the stimulus spending trends of the PSIs. It does this by aggregating the publicly available state stimulus spending of the Global Recovery Observatory (GRO) by PSI (Global Recovery Observatory, 2021), with the GRO being the most comprehensive database launched on state stimulus measures thus far. Third, it explores the GGND as an analytical tool yielded by potential norm entrepreneurs, namely the G7. As a result, this communication intends to identify nascent trends in the norm entrepreneurship of the GGND among PSIs and identify further opportunities and barriers for further norm diffusion in global society.

\section{The Global Green New Deal}

The green new deal was a term first coined in 2007 by political commentator Thomas Friedman who described it as a "huge industrial project" to develop industry fuelled by clean power (Friedman, 2007). Yet, it was the United Nations Environment Program (UNEP) that first launched a comprehensive plan for the GGND in 2009 in response to the Global Financial Crisis (GFC) (UNEP, 2009). The UNEP describes the GGND as a policy package with the objectives of reviving the world economy, reducing carbon dependency and furthering sustainable growth (UNEP, 2009: p. 5). UNEP's definition of a GGND includes three elements: economic stimulus, domestic regulatory reform, and international cooperation (UNEP, 2009: pp. 5-6).
The first element is state-led economic stimulus that decarbonises carbon-intensive sectors of the economy such as energy, transport, buildings and agriculture (UNEP, 2009: pp. 6-9). The second element is domestic policy reform (UNEP, 2009: pp. 9-12). Policy reform options include eliminating environmentally harmful subsidies and strengthening environmental legislation (UNEP, 2009: pp. 9-12). Complementary to this domestic stimulus and policy reform is a third element of international coordination (UNEP, 2009: pp. 12-16). This element includes changes to the policy architecture governing international trade, aid, global carbon markets and technology transfers (UNEP, 2009: pp. 12-16). While domestic implementation of a green stimulus and policy measures are no doubt important for the GGND, it is the international element where it's global nature becomes most apparent.

While there was limited uptake of the GGND's in response to the GFC, recent legislative and policy proposals illustrate its normative resurgence (Boyle et al., 2021: p. 1). The European Union, the United Kingdom and South Korea have crafted policy plans for their own local green new deals (European Commission, 2019; HM Government, 2020; Government of the Republic of Korea, 2020). Green New Deal Bills have also been tabled in the United States, the United Kingdom and Australia (United States' Congress, 2019; House of Commons, 2019; Commonwealth Government, 2020). Green new deals have also been launched in a number of states and cities, particularly in the United States (Boyle et al., 2021: p. 5). While these legislative and policy proposals have had mixed success, they have been further amplified by calls to "build back better' from COVID-19 (United Nations, 2020). This includes by way of an 'climate and environment responsive approach to COVID-19 recovery efforts' (United Nations General Assembly, 2020: art 47). Such an approach involves states implementing the GGND through state-led domestic green stimulus to reach net-zero emissions by 2050 or sooner (P4G Summit Seoul, 2021). The complementary role of international organisations in coordinating the 'global' element of the GGND is also increasingly recognised (International Monetary Fund, 2021; Malpass, 2021). However, in recognising early norm entrepreneurs of the GGND, one should be careful not to discount the parallel role played by norm antipreneurs- actors that resist normative change (Bloomfield and Scott, 2017). Russia has, for example, stressed the need to keep climate change and economic development separate and threatened action at the World Trade Organisation against measures such as the carbon border adjustment mechanisms, which can be used to operationalise green deals (European Commission, 2021; Tass, 2021; Morgan S, 2020). Both state and international institutions form a 'community of practice' of the GGND, one which norm entrepreneurs form part of and antipreneurs target (Brunnée and Toope, 2010: p. 45; Bloomfield and Scott, 2017).

The above window into practice of the GGND reveals that it should not be considered a singular norm, but rather an example of a 'norm bundle' that sees further adaptation and diffusion depending on national circumstances. A norm bundle features a combination of fundamental norms, organising principles and standards and procedures (True and Wiener, 2019). From a climate perspective, an example of a fundamental norm contained within the GGND is that of 'energy transition', which is reflected in both the GGND's domestic and international paradigms. Domestic stimulus and policy reform is necessary to both fund and lower regulatory barriers for an energy transition to renewable energies. International coordination is also essential to ensure diffusion of the energy transition and address barriers to 
local adaptation. An example of an organising principle embedded within the GGND is the climatisation of financial flows by aligning them to 'net-zero'. This principle is also reflected in a range of standards and procedures such as efforts to align the terminology of green finance in the recent creation of the Glasgow Financial Alliance for Net Zero and the International Sustainability Standards Board (UK COP26, 2021a). Procedures that allow for environmental integrity of cross-border carbon accounting also remain key. These examples from the climate aspects of the GGND norm bundle remain nascent and subject to a large degree of contention between norm entrepreneurs and antipreneurs. Yet many commonalities exist in its various expressions, indicating that it does, at present, possess normative momentum. In order to investigate this further, it is necessary to examine the GGND from the position of the major players of global governance- the PSIs.

\section{Global governance and plurilateral summit institutions}

Developments in international relations are not apparent 'exante' but instead are the result of 'social processes' (McCourt, 2016: p. 475). Global governance approaches to international recognise that these social processes are no longer the foray of states alone, but rather a broader notion of 'global society'-a dense network of both state and sub-state actors that share common values (Barnett and Sikkink, 2011: p. 749). This shift to global society prompted enquiries into how normative agendas are constructed, how international and domestic structures shape governance structures and the broad range of actors involved in international relations (Barnett and Sikkink, 2011: pp. 755-756). More recently, scholarship has also grappled with wider issues of norm conflict and contestation (Bloomfield and Scott, 2017). Considering how norms develop in these respects is crucial to understanding the normative role that PSIs may play. PSIs possess a unique character in international relations given their informal structure that is both wholly constituted and constrained by their respective member states'. Owing to the informal structure of PSIs their practice is largely reflected in the aggregate of the practice of their individual member states'. On the other hand, PSIs agree their normative position via consensus. Consequently, this consensus often represents the lowest common denominator of agreement on key issues. Relationality to a norm can thus change significantly depending on the global governance grouping- even when states may be present in more than one PSI. In recognition of this, this contribution adopts the 'twin approach' of practicerelationism in order to more deeply contextualise nascent trends of norm entrepreneurship of the GGND within global governance.

Norm development. How norms develop is a fundamental concern of the constructivist school of IR. A useful framework in approaching this question is Finnemore and Skikkinks' (1998; p. 898) notion of a 'norm lifecycle'. A complete 'norm lifecycle' involves three key stages of emergence, cascade and internationalisation. While not every norm will complete or even advance beyond the norm emergence phase- Finnemore and Skikkink's framework helps underscore norm building as a continual process (Finnemore and Sikkink, 1998: p. 895). The norm lifecycle begins with norm 'emergence', where 'norm entrepreneurs' seek to persuade other network participants of the value of a norm. From here norms may reach the stage of 'cascade', where through socialisation, states and other actors see norm adoption as a means of enhancing their legitimacy (Finnemore and Skikkink, 1998; p. 898). If norms have reached the tipping point of cascade, they may still continue onwards to become internalised within the system. It is at the stage of 'internationalisation' where conformity with norms is sought and is reflected in a number of professional and bureaucratic settings such as law and policy (Finnemore and Skikkink, 1998; p. 898). There are a range of factors individual to the setting of a norm that affect the success of norm diffusion and adaptation to local contexts in the latter two stages of the norm lifecycle, and also form determinants of the overall success of the norm or norm bundle in global governance (Finnemore and Skikkink, 1998; pp. 905-909).

Finnemore and Skikkink underscore that completion of the norm lifecycle 'is not inevitable' (Finnemore and Sikkink, 1998: p. 895). Instead they recognise that 'many emergent norms fail to reach a tipping point' from emergence to cascade (Finnemore and Sikkink, 1998: p. 895). Nevertheless, sole appreciation of the role of norm entrepreneurs in the norm lifecycle can present an overly optimistic picture of norm diffusion. To remedy this Bloomfield and Scott (2017) introduce the conceptual phenomena of norm antipreneurs and outline how their cognition can result in a more balanced assessment of the norm generation process. Such an addition instantiates the notion of a norm lifecycle (Finnemore and Sikkink, 1998) and highlights the broader deficiencies in IR's adoption of the logic of appropriateness and the logic of consequences in explaining social change (McCourt, 2016: p. 478; Sending, 2002). Accordingly, this contribution views the norm lifecycle as one akin to that belonging to a human: a process that features a birth, a death and a full range of unique events and adaptations that can either extend or shorten a given lifecycle. This analogy extends to norm bundles, which can be viewed as a norm 'family' that contains norms at different stages of the norm lifecycle but that nonetheless interact with each other. Indeed, even within this 'norm family' some individual norms and even the whole norm bundle may still fail to develop. The heterogeneity of norm development in this regard should be borne in mind when assessing the relationship between PSIs and the GGND.

The role of PSIs. PSIs are 'club-based' governance mechanisms that straddle the divide between states and international institutions (Brandi, 2019). Given the changing dynamics of the global world power configuration three institutions are of particular importance: the G7, the G20 and the BRICS (Jang et al., 2016). The G7 was founded in 1975 as a grouping of 'open, democratic and outward-looking societies' (G7, 2021a). At present, it includes Japan, Canada, the United Kingdom, the United States, France, Germany and Italy. Then in 1999, the G20 emerged with a view to reflecting the views of both eminent and emerging economies. The G20 comprises of the G7, plus Argentina, Australia, Brazil, China, India, Indonesia, South Korea, Mexico, Saudi Arabia, South Africa, Russia, Turkey and the European Union. Lastly, the BRICS was founded in 2006 in recognition of the unique position of the large emerging economies of the G20. BRICS members include Brazil, Russia, India, China and South Africa. The loose structure and varied membership of these 'club' based institutions means that they may not be explicitly driven by a coherent rationale or consensus among their members (Viola, 2019). This can create a 'governance gap' whereby there is a long-term discrepancy between the action required and the action taken in a given issue area (Viola, 2019). In club-based institutions it may be that 'the individual interests of multiple states may paradoxically be to their collective detriment in the future, even as crises loom larger' (Fioretos, 2011). These aspects, alongside the clear overlap in membership between the G7, the G20 and the BRICS, highlight the complex dynamics of PSIs, which foreground the entrepreneurial role they may play in relation to the GGND. 
As a norm bundle, the GGND has and will continue to be subject to a high amount of contention. There are indications that PSIs are prime fora for this norm consolidation and contestation and thus hold the key to further diffusion. Indeed, PSIs have assumed prominence in global economic governance. PSIs are increasingly also recognising the interrelationships between economic policy and cross-cutting issues of climate change and sustainable development (Johnstone, 2021). In the post-COVID19 economic recovery, PSIs are once more presented with an opportunity akin to that from the Global Financial Crisis to 'build back better' (Johnstone, 2021). While slow to respond to the COVID-19 crisis initially, the G20 summit in November 2021 resulted in the greatest commitment to a green recovery seen to date (G20 Leaders, 2021). Yet the language in the final communiqué regarding climate and energy issues was ultimately weaker than the zero draft up for negotiation (Euro News, 2021). This difference was largely ascribed to contention between the G7 and BRICS, a feature that is potentially indicative of different collective positions regarding the GGND (Chatham House, 2021). The BRICS tend to view climate and economic issues as separate, having underlined the importance of common but differentiated responsibilities in their most recent New Delhi Declaration (Xinhua, 2021). On the other hand, the G7 more strongly signalled a commitment to a green recovery in their most recent communiqué (G7, 2021b; Lawder, 2021). To interrogate these trends further, it is necessary to gain a sense of the practice and relationality of the GGND among PSIs.

Practice of PSIs. Practice among PSIs member states, as largescale players in global governance, are an essential determination of the likely success of its diffusion as a norm bundle. The 'practice turn' in international relations reflects the core constructivist understanding that the norms that shape our reality are not innate but rather constructed through practice (McCourt, 2016: p. 477). Given the GGND's recent normative resurgence, in tandem with the ongoing economic recovery from COVID-19, its practice remains nascent. Yet this has not stopped a number of attempts to track green recoveries. Current empirical assessments tend to concentrate on the green recovery profiles of individual countries (Vivid Economics, 2021) or aggregate to worldwide assessments (O'Callaghan and Murdock, 2021). As such, they are ill-suited for the purpose of identifying norm entrepreneurship patterns in the middle ground of PSIs. This contribution fills this lacuna by undertaking aggregate analysis of the practice catalogued by the GRO of the G7, G20 and (GRO, 2021). With the results of this novel empirical analysis it becomes possible to analyse the trends in norm emergence among PSIs, from which one can assess any potential governance gap going forward. While such analysis may provide a useful snapshot of the practice of PSIs it needs to be further complemented with an understanding of their relationality of PSIs with the GGND.

Relationality of PSIs to the GGND. Practice alone does not a norm make as norm making is an inherently dynamic process built on social relations. Relationality in IR refers to the way in which 'relations are aggregated and used to stabilise and reify' the object under observation (McCourt, 2016: p. 479; Sending et al., 2015: p. 7). This definition challenges IR scholars to not view 'objects' or 'units' as self-evident, but instead to engage with 'relations' that constitute them (Trownsell et al., 2019). Applied to the case at hand, the relations are those that belong to the respective PSIs concerning the GGND. They are both internal, in the sense that PSIs are the sum of the parts of their members. Consequently, domestic green recovery practice and rhetoric aggregates to reflect a given PSI's position on the as a GGND norm bundle. They are also external in the sense that collective practice of different PSIs helps also advance or contest conceptions of the GGND as a norm bundle, signalling potential roles as collective norm entrepreneurs and antipreneurs. Considering both internal and external elements of relationality also helps explain the contextual malleability the GGND has seen between the notions of a 'green recovery', 'green industrial revolution' and 'building back better'. It further reflects of the fact that norms themselves are not static but are instead 'continuously reconstructed' (Hofferberth and Weber, 2015: p. 85). This study seeks only to provide a current snapshot given the nascency of the GGND. Nevertheless, in doing so, it aims to provides a unique insights for global governance regarding PSI's practice of and relationality to the GGND.

\section{Governance patterns of the Global Green New Deal}

To distinguish global governance trends in relation to the GGND, the author first undertook novel interrogation of the open-source stimulus data provided by the GRO (Global Recovery Observatory, 2021). The GRO's objective is to classify all fiscal policy measures that form part of the economic rescue and recovery to COVID-19 in a selected range of countries. For this task, the GRO created an exhaustive system of 5 typologies, 40 archetypes and 158 sub-archetypes and has applied it to 90 entities: 88 states, the European Union and the European Investment Bank- making it the most significant attempt to catalogue and archetype stimulus ever published. The researchers of the GRO then used a sophisticated Likert assessment to determine the environmental, social and economic policy impacts of these policy archetypes (O'Callaghan et al., 2021; p. 6). Assessments of greenhouse gas emissions under the archetypes are uniquely subject to consideration of both the short-term and long-term emissions profiles given the differential impact both bring (O'Callaghan et al., 2021: p. 6). In this way archetypes are categorised to clearly distinguish between policies that support and harm the objective of combatting climate change (O'Callaghan et al., 2021; p. 6). It is on this basis that the GRO categorises policy archetypes as either 'clean' or 'dirty' stimulus. 'Clean' stimulus includes measures such as investment in renewable energy or clean transport. 'Dirty' stimulus includes measures such as investments in oil and gas operations as well as airlines. Supplementary Annex A provides a detailed overview of the nature and relative importance of these archetypes through collating the most significant clean and dirty policy that each PSI member state employed.

The GRO's database relates solely to measures that have been committed to by the entities it tracks, and crucially continues to be regularly updated as the response to COVID-19 continues to evolve (Global Recovery Observatory, 2021). This research summarises the total number of measures and policy archetypes for each state. It then aggregates, as appropriate, to their respective PSIs in order to provide an overall empirical assessment of proportionally how 'clean' the stimulus packages of each entity is. This contribution bases its analysis on the most recent data available from October 11, 2021. It also provides a contrast between this dataset and the previous release of May 24, 2021 to demonstrate the changes between iterations and underscore the unfolding nature of both the stimulus practice itself as well as its capture by the Global Recovery Observatory. As such, it provides an initial, if constrained, empirical perspective on the individual and collective green recovery practice of the entities that comprise the G20, G7 and the BRICs.

Table 1 demonstrates the results of novel interrogation of the Global Recovery Observatory's stimulus data by PSIs. 
Table 1 Breakdown of plurilateral summit institutions' green recoveries as at May 24 2021/ Oct 112021.

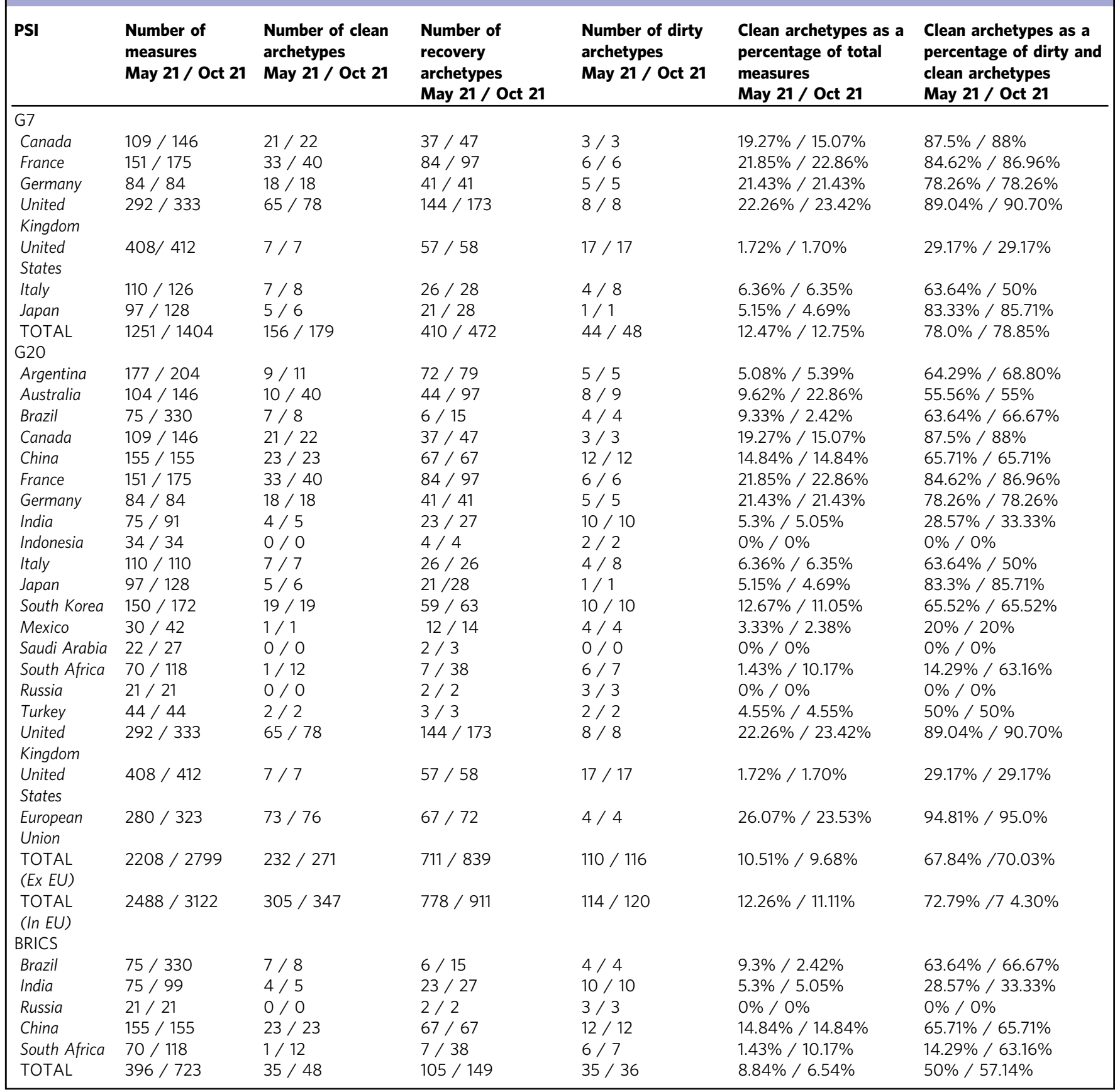

Promisingly, it shows that all PSIs implemented a higher proportion of clean policies than dirty in October 2021. Yet it also reveals considerable and persistent divergence between the G7, the G20 and the BRICS in terms of the proportion of clean measures to dirty. It reveals that the G7 are consistently implementing a higher proportion of clean measures in their stimulus packages. The G20 on the other hand, demonstrates considerably more heterogeneity across its member states, with Russia and Indonesia implementing zero clean archetypes in contrast to the European Union, which implemented on average 19 clean archetypes for every dirty archetype-a feature of the data that remained consistent both in May and October 2021. Table 1 also illustrates the strong influence the European Union have on the proportion of clean stimulus measures employed by the G20, bringing it up to an overall percentage of $74.30 \%$, up from $70.03 \%$ when it is excluded. It further reveals that the BRICS have implemented less clean measures as a proportion than the G7 and G20. However, despite Russia not having implemented any clean measures, overall the BRICS now also fund proportionally more clean than dirty measures.

The results of Table 1 should be considered alongside its limitations. The data changes between May and October 2021 reflected in Table 1 reveal that the process of stimulus package design and implementation is one that remains ongoing. For this reason the utility of these figures should only be viewed as a limited snapshot, not full picture, of the green recovery practice of PSIs. Furthermore, this assessment focuses in on the direct proportion between clean and dirty measures as being an indication of the trends in the green recoveries among PSIs. However, for most measures the GRO also provides data on the economic size 
of most measures (both in real terms and standardised to the US dollar). To aid in fair comparison of the overall climate impact of stimulus packages Supplementary Annex A provides an illustrative example of the largest clean and dirty policy measure of each PSI member state. Other studies are also available that contain and assess the economic size of the stimulus packages and their green proportions (O'Callaghan and Murdock, 2021; Vivid Economics, 2021). In time these studies can be complemented from a PSI-specific lense once the GRO publishes their final dataset on the COVID-19 response measures and their respective financial size.

Analysing the proportions of clean measures as against the other categories of total and dirty measures also risks oversimplifying a complex policy matrix. This oversimplification can be seen in the second aspect of assessing the practice of PSIs member states- the fact that GRO does not reflect all stimulus measures that may be at play in a given state or region. For example, the actual proportion of clean stimulus may well be higher for G7 and the G20, as the measures of the European Investment Bank, which has overwhelmingly funded clean measures in its recipient states, are excluded from the results. The effect of stimulus provided by international institutions such as the World Bank and International Monetary Fund (IMF) also remains excluded from the GRO data. Moreover, the full details of some stimilus packages remain unfinalised- the best example of this in January 2022 being the Build Back Better proposals of President Biden in the United States (White House, 2021a). All of these aspects underscore that as COVID-19 continues to unfold, so too will policy measures in response to it. Thus, a final analysis may not be possible for several years to come. However, in the meantime, these results present a snapshot of current PSI practice. A snapshot that remains subject to the many limitations outlined above.

\section{Contemporary norm entrepreneurship of the Global Green New Deal}

The above empirical analysis provides early insights as to trends in green recovery practice among PSIs. This practice analysis identifies that it is the G7 who are the predominant grouping advancing the GGND in practice. Clean measures employed by the G7 out measure dirty ones by a proportion of 3:1. Yet, green stimulus and domestic policy reform comprises just two of three elements of the GGND. To assess the G7 further as potential norm entrepreneurs it is first necessary to consider how its members continue to build a shared consensus of the GGND as a norm bundle internally and externally. This includes consideration of the historical role the G7 plays in addressing climate change, the domestic strategies its members employ and early signs the G7 is pursuing norm diffusion of the GGND. However, the nascency of this trend must be underscored. There also remains several barriers to further norm diffusion. While there is a disjunct in the practice and relationity between the G7 and the BRICs regarding the GGND, growth in green recovery practice is advancing at a faster higher rate among the BRICS than the G7. For this reason, the line between norm entrepreneur and antipreneur among these PSIs cannot yet be drawn for the GGND. Instead, it becomes clear that a key determinant of the G7's success in globalising the green new deal will be that of partnership among PSIs that both addresses barriers to norm diffusion and drives local adaptation across the globe.

The G7 as potential norm entrepreneurs of the GGND. Environmental issues have long been on the agenda of the G7. In 1978 its leaders recognised the importance of the environment in energy development and in 1979 they recognised the need to limit the concentration of carbon dioxide in the atmosphere (Kirton et al., 2018: p. 94; Kirton et al. 2018). After a decade of pioneering the global response to climate issues, the G7 in 1988 called for the United Nations Framework Convention on Climate Change to be set-up and later adopted the same approach when it became the major PSI pushing for a climate change framework postKyoto Protocol that included all emitters, not just developed nations (Kirton et al., 2018: p. 94; Kirton et al., 2018). Despite the G7 taking a comparatively early governance lead on climate issues they still face an governance gap; one caused by the changing priorities of its hosts, its lack of secretariat and its unmonitored delegation of climate issues to actors such as the World Bank and IMF (Kirton and Kokotsis, 2015: p. 6). Nevertheless, empirical analysis of the climate commitments of PSIs reveals that the G7 has the highest compliance at an average of $72 \%$ in contrast to the G20 with 68\% (Kirton et al., 2018: 97) and the BRICs whose climate policy is still developing (Martins, 2019). This reflects that climate change has been a core focus of the G7, while it has not in the G20 and the BRICS (Bracht and Nguyen, 2018: p. 172). This background informs the legitimacy of the G7 as norm entrepreneurs in the global governance of climate issues. The G7's potential role as norm entrepreneurs of the GGND will now be examined by canvassing their relevant domestic practice and assessing their collective aspirations as a PSI.

Internal relationality. The domestic practice of G7 states in support of a green recovery reflects a normative consensus that they as a collective of relations seek to 'build back better' (G7, 2020b). All G7 member states have indicated that a green recovery is a major policy priority in their individual responses to COVID-19. During Canada's 2020 throne speech, their Governor General outlined that 'building back better' was to be a major foundation of the upcoming legislative agenda (Government of Canada, 2020a). Putting this into effect, their 2021 budget directs CAD \$17.6 billion to the green recovery (Government of Canada, 2021: p. 160); funding that operates in tandem with introducing environmental conditionality to job-protective stimulus in the oil and gas industry (Government of Canada, 2020b). France has also sought to implement environmental conditionality in areas such as the bailout of their national airline, Air France, and the banning of certain short-haul flights where a train alternative is available (Vivid Economics, 2021: p. 42). Such policy measures complement France’s EUR $€ 30$ billion 'ecological plan' for a green transition (Vivid Economics, 2021: p. 42). Germany has announced a EUR $€ 50$ billion 'Package for the Future', which includes investment in renewable energy and sustainable transport (Government of Germany, 2020). The United Kingdom has also announced a $£ 12$ billion GBP for a 'Green Industrial Revolution' (HM Government, 2020). This operates in tandem with complementary policy measures, such as the North Sea Transition Deal, which aims for a 'just transition' for oil and gasdependent communities during decarbonisation efforts (HM Government, 2021). Italy has announced a 'green revolution and ecological transition' as a cornerstone of its policy response to COVID-19 and has ensured that $40 \%$ of its stimulus is going 'to combat climate change' (Government of Italy, 2021). In December 2020, Japan's new Prime Minister Suga announced a EUR $€ 17.5$ billion fund towards achieving a new nationally determined contribution for Japan of net-zero emissions by 2050 (Bouckaert, 2021: 3). Finally, in the United States, the Biden Administration has successfully passed the Build Back Better Bill through the first step of the legislative process- the House of Representatives (White House, 2021a). This Bill being set to deliver USD \$2.2 trillion of spending will green infrastructure over the next decade (Cochrane and Weisman, 2021). Therefore, while G7 states have differing degrees of domestic ambition and 
timescales, all have demonstrated active interest in green stimulus and policy measures. This contributes to the strong relationality seen at the G7 Carbis Bay Summit between the G7 and the norm bundle of the GGND. Nevertheless, should the G7 wish to avoid a governance gap in this regard, it is important that the effects of implementing clean stimulus are not neutralised or reversed by parallel investment in dirty stimulus as this could threaten to undermine their internal relationality with the GGND and their legitimacy as possible norm entrepreneurs more broadly.

External relationality. The intention of the G7 to play an external norm entrepreneurship role in the GGND norm bundle was most clearly demonstrated at their Carbis Bay Summit held in 2021. There, G7 Leaders endorsed a plan for a 'Build Back Better World', otherwise known as the B3W plan (White House, 2021b). The $\mathrm{B} 3 \mathrm{~W}$ plan is intended to catalyse hundreds of billions of dollars of infrastructure investment for low-and middle-income countries in the coming years (White House, 2021b). The plan has four pillars: climate, health and health security, digital technology, and gender equity and equality (White House, 2021b). Currently, a particular priority of the $\mathrm{B} 3 \mathrm{~W}$ plan is clean and green growth to drive a sustainable and green transition in line with the Paris Agreement and Agenda 2030 (G7, 2021b: [67]). A Build Back Better summit was also held by President Biden on the side-lines of COP26. This saw further commitments by the G7 and crucially partnerships with broader partners. The United Kingdom and India jointly announced the 'Green Grids Initiative' in a declaration supported by over 80 states, with the object of mobilising political will, finance and technical assistance (UK COP26, 2021b). A 'Political Declaration focused on a Just Energy Transition in South Africa' was also announced at COP26. This being a partnership between South Africa, the United Kingdom, the United States, France, Germany and the European Union focused specifically on shortterm finance to support the decarbonisation of South Africa-the world's most carbon-intensive electricity producer (UK COP26, 2021c). The signatories also expressed their hopes that it would become a test case for other economic transitions including Indonesia and India and in this tangible models of norm diffusion (UK COP26, 2021c). In these ways the G7 is beginning to align its internal relationality, with its external relationality, particularly between BRICS member states.

Outlook for globalising the Green New Deal. While the green recovery appeared a major theme at COP26, it more broadly highlighted the work still do be done by norm entrepreneurs to further convince other actors of the utility and accessibility of a comprehensive GGND. When considering the outlook for normative diffusion of the GGND there are three important issues, which will likely affect its success of cascade and internationalisation: congruency of practice, local adaptation and barriers to diffusion. From a legal perspective, these issues crucially also reflect the extent of state practice and opinio juris that the GGND as a norm bundle generates. For global governance of the GGND norm bundle they outline importance of legitimate norm entrepreneurship and diffusion among PSIs and beyond.

Congruency of practice. The G7 appear to be norm entrepreneurs of the GGND through their domestic and collective practice. However, these mechanisms of entrepreneurship remain nascent, meaning the GGND is still likely at the norm emergence phase of the norm lifecycle (Finnemore and Skikkink, 1998; p. 898). During the emergence phase of norms, the congruency of norm entrepreneurs between their action and the norm bundle is an essential part of ensuring its legitimacy. It is also the time when norms are most vulnerable to attack or interest capture from norm antipreneuers. As the practice analysis above has revealed, domestic green recoveries are an active and ongoing process on the part of PSI members, a feature, which has seen considerable evolution between May and October of 2021 per Table 1. Efforts to promote international congruency of the GGND remain even more nascent and considerably more controversial as the current contention over carbon border adjustment mechanisms reveals. Assessing the consistency of domestic and international practice of norm of the G7 will therefore be a crucial determinant of their success as norm entrepreneurs of the GGND. From a legal perspective, how 'widespread' and 'representative' such practice is will also inform the extent to which a norm of the GGND could be considered legal in future. For these reasons, congruency of practice is essential to addressing the 'governance gap' that PSIs such as the G7 have long been challenged with particularly concerning climate issues.

Local adaptation. The disparate effects of the twin-crises of climate change and COVID-19 have produced divergent baselines from where countries seek to 'build back better' from. From an empirical perspective, the divergence in clean stimulus between the G7, G20 and the BRICS brings with it the risk that the GGND is only seen as applicable to developed nations. This underscores the vital importance of local adaptation of the GGND as a norm bundle in a manner that is appropriate to local contexts and needs. Such rhetoric was mirrored during interventions by BRIC members India and China in the closing of COP26. It is further reflected in efforts by the G7 to 'green' their international development projects such as the Build Back Better World Partnership. The challenge for norm entrepreneurs will be ensuring frameworks such as the GGND are able to not only be transplanted but to truly be adapted to and adopted by local contexts. Individual plans for net-zero, such as that released for India, will play a key role in this (World Economic Forum, 2021). Such opportunities highlight that 'localisation' of green new deals will prove crucial to their 'globalisation'.

Barriers to diffusion addressed. Norm entrepreneurs must ensure that the opportunity to implement the GGND bundle is available to all states through adequate provision of financing and capacity building measures. The GGND as a norm bundle presents an opportunity for economic development and decarbonisation to occur in tandem. If tailored appropriately to local circumstances the GGND can result in an opportunity to 'leapfrog' state infrastructure; for example, by bypassing natural gas infrastructure that is viewed as a 'transition fuel' to instead invest renewable energy directly. Nevertheless, as the GGND is fundamentally a stimulus led norm bundle, states with limited fiscal space, particularly postCOVID-19, must receive adequate assistance in implementing its strands. The negotiation of close to $\$ 100 \mathrm{bn}$ of climate financing at COP26, in addition to the green conditionality to loans will go some way to assist in this transition. Other opportunities to advance collaboration, such as the newly adopted rules on carbon market and non-market mechanisms under the Paris Agreement, may also be used to address barriers to diffusion. In these ways international coordination forms a central element of the operationalising the GGND. However, despite promising rhetoric by the G7 in this regard, such plans remain only that at this nascent stage of the GGND's norm lifecycle. Therefore, the G7 working to overcome the governance gap in external coordination of the GGND will likely prove crucial to its norm diffusion.

\section{Conclusions and outlook}

This communication explored the GGND through the multipronged lense of global governance. By mapping the GGND as a 
policy notion, it makes clear the role of states both individually and collectively in enacting a GGND. Yet it also highlights how the role of PSIs has often been overlooked within the GGND's community of practice and in 'building back better' from COVID-19. By applying an empirical lense to the GGND, this contribution offers preliminary insights into green recovery trends among the G7, the G20 and the BRICS. It identifies the G7 as potential norm entrepreneurs of the GGND, a feature which accords with its long-standing history as a pioneer of collective climate and environment commitments (Kirton et al., 2018: p. 94; Kirton et al., 2018). The GGND norm entrepreneurship of the G7 is then assessed analytically, both as individual states and as a collective. Underpinning these insights is an appreciation of the GGND's stage within the norm lifecycle, including its current stage of norm emergence and the present barriers that need to be overcome in order for norm diffusion to begin.

Norm evolution remains an inherently dynamic process. Indeed, the GGND's reinvigoration through calls to 'build back better' to COVID-19 stands testament to this. This communication is intended to offer preliminary insights as to the relationship between the GGND, global governance and the G7. Further empirical and normative analysis is needed to explore these trends, particularly from the perspective of PSIs, which tend to be overlooked in current assessments as to whether or not the world is 'building back better' (Vivid Economics, 2021; O'Callaghan and Murdock, 2021). This research agenda also has the potential to unlock more granular insights into the heterogenous impact of COVID-19, climate change and the implications of this for the appropriate economic response. The analysis of the practice of PSIs, and their relationality to the GGND, also casts open the door for future analysis on how the constitution of practices reflects and structures the identities of PSIs (Sending, 2002, p. 463). Such research could demonstrate that with its unique enmeshment of domestic and international elements, the GGND is much more than the sum of its parts and so too are PSIs. Global governance approaches to international relations can capture this complexity and in doing so, can unlock insights as to how the GGND can truly embody its global nature in future.

\section{Data availability}

The datasets analysed during the current study are available in the Dataverse repository: https://doi.org/10.7910/DVN/JBWVIC. This dataset was derived from the Global Recovery Observatory's publicly available datasets released on May 242021 and October 112021 and can be accessed here: https://recovery.smithschool.ox.ac.uk/tracking/.

Received: 7 September 2021; Accepted: 12 January 2022;

Published online: 01 February 2022

\section{References}

Barnett MN, Sikkink K (2011) From international relations to global society. In: Goodin R (ed) The Oxford handbook of political science. Oxford University Press, Oxford, pp. 748-765

Bloomfield A, Scott S (2017) Norm Antipreneurs in world politics. In: Bloomfield A, Scott S (eds) Norm antipreneurs and the politics of resistance to global normative change, 1 edn. Routledge, Abingdon

Bouckaert E (2021) Japan's 2050 net-zero emission policy: a case for degrowth?. EIAS. https://www.eias.org/wp-content/uploads/2019/07/JAPANS-2050NET-ZERO-EMISSION-POLICY-A-CASE-FOR-DEGROWTH.pdf. Accessed 23 May 2021

Boyle AD, Leggat G, Morikawa L, Pappas Y, Stephens J (2021) Green New Deal proposals: Comparing emerging transformational climate policies at multiple scales. Energy Res Soc Sci 81:1-8. https://doi.org/10.1016/j.erss.2021.102259

Bracht C, Nguyen H (2018) Comparing G7/8, G20 and BRICS compliance. In: Kirton J, Larionova M (eds) Accountability for effectiveness in global governance, 1 edn. Routledge, New York, NY, p 172
Brandi C (2019) Club governance and legitimacy: the perspective of old and rising powers on the G7 and the G20. S Afr J Int Aff 26(4):687. https://doi.org/ $10.1080 / 10220461.2019 .1697354$

Brunnée J, Toope SJ (2010) Legitimacy and legality in international law. Cambridge University Press, Cambridge

Chatham House (2021) G20's lack of progress highlights challenge for COP26. https://www.chathamhouse.org/2021/11/g20s-lack-progress-highlightschallenge-cop26. Accessed 20 Nov 2021

Cochrane E, Weisman J (2021) House narrowly passes biden's social safety net and climate bill. The New York Times. https://www.nytimes.com/2021/11/19/us/ politics/house-passes-reconciliation-bill.html. Accessed 20 Nov 2021

Commonwealth Government (2020) Green New Deal (quit coal and renew Australia) bill. https://www.aph.gov.au/Parliamentary_Business/Bills_Legislation/ Bills_Search_Results/Result?bId=r6512. Accessed 11 Nov 2020

Euro News (2021) G20: leaders make mild pledges on carbon neutrality and coal financing as COP26 begins. https://www.euronews.com/2021/10/31/g20leaders-turn-to-climate-change-on-last-day-of-summit-as-focus-shifts-tocop26.Accessed. Accessed 21 Nov 2021

European Commission (2019) The European Green Deal. https://eurlex.europa.eu/legal-content/EN/TXT/?uri=COM\%3A2019\%3A640\%3AFIN. Accessed 22 Dec 2020

European Commission (2021) Proposal for a Regulation of the European Parliament and of the Council establishing a carbon border adjustment mechanism. https://ec.europa.eu/info/sites/default/files/carbon_border_adjustment _mechanism_0.pdf. Accessed 20 Jul 2021

Finnemore M, Sikkink K (1998) International norm dynamics and political change. Int. Organ 52(4):887-917. https://doi.org/10.1162/002081898550789

Fioretos O (2011) Historical institutionalism in international relations. Int Organ 65(2):367-399

Friedman TL (2007) The power of green. https://www.nytimes.com/2007/04/15/ opinion/15iht-web-0415edgreen-full.5291830.html. Accessed 2 Jun 2021

G20 Leaders (2021) G20 Rome Leaders' Declaration. https://www.google.com/ search?channel $=$ trow5\&client $=$ firefox-b-d\&q $=\mathrm{g} 20+$ summit + declaration. Accessed 2 Nov 2021

G7 (2021a) What is the G7. https://www.g7uk.org/what-is-the-g7/. Accessed 22 Jun 2021

G7 (2021b) Carbis Bay Communiqué. https://www.consilium.europa.eu/media/ 50361/carbis-bay-g7-summit-communique.pdf. Accessed 21 Jul 2021

Global Recovery Observatory (2021) Global Recovery Observatory https:// recovery.smithschool.ox.ac.uk/tracking/. Accessed 20 Oct 2021

Government of Canada (2020a) Speech from the Throne. https://www.canada.ca/en/ privy-council/campaigns/speech-throne/2020/speech-from-the-throne.html. Accessed 1 Apr 2021

Government of Canada (2020b) Canada's COVID-19 economic response plan: new support to protect Canadian jobs. https://www.canada.ca/en/ department-finance/news/2020/04/canadas-covid-19-economic-responseplan-new-support-to-protect-canadianjobs.html\#Orphan_and_inactive_oil. Accessed 30 Apr 2021

Government of Canada (2021) A recovery plan for jobs, growth, and resilience. https://www.budget.gc.ca/2021/home-accueil-en.html. Accessed 30 Apr 2021

Government of Germany (2020) Stimulus package for everyone. https:// www.bundesfinanzministerium.de/Web/EN/Issues/Public-Finances/ stimulus-package-for-everyone/stimulus-package-for-everyone.html. Accessed 3 May 2021

Government of the Republic of Korea (2020) Korean new deal: national strategy for great transformation. https://english.moef.go.kr/pc/selectTbPressCenterDtl. do?boardCd=N0001\&seq=4948. Accessed 10 Mar 2021

HM Government (2020) The ten point plan for a green industrial revolution. https://www.gov.uk/government/publications/the-ten-point-plan-for-agreen-industrial-revolution. Accessed 12 Dec 2020

HM Government (2021) North sea transition deal. https://assets.publis hing.service.gov.uk/government/uploads/system/uploads/attachment_data/ file/972520/north-sea-transition-deal_A_FINAL.pdf. Accessed 4 May 2021

Hofferberth M (2016) "Confusion is a fundamental state of mind"-On the peculiar intellectual career of global governance in international relations. Palgrave Commun 2:15044. https://doi.org/10.1057/palcomms.2015.44

Hofferberth M, Weber C (2015) Lost in translation: a critique of constructivist norm research. J Int Relat Dev 18(1):75-103

House of Commons (2019) Decarbonisation and economic strategy bill. https:// bills.parliament.uk/bills/2758. Accessed 11 Nov 2020

International Monetary Fund (2021) https://www.imf.org/en/News/Articles/2021/ 04/15/sp041521-securing-a-green-recovery. Accessed 25 Apr 2021

Jang J, McSparren J, Rashchupkina Y (2016) Global governance: present and future. Palgrave Commun 2:15045. https://doi.org/10.1057/palcom ms. 2015.45

Johnstone I (2021) The G20, climate change and COVID-19: critical juncture or critical wound? Fulbright Rev Econ Public Policy https://doi.org/10.1108/ FREP-05-2021-0031 
Kirton J, Kokotsis E (2015) The global governance of climate change: G7, G20 and UN Leadership. Ashgate, Farnham, p 6

Kirton J, Kokotsis E, Warren B (2018) G7 governance of climate change. In: Oldani C, Wouters J (eds) The G7, anti-globalism and the governance of globalization, 1 edn. Routledge, New York, NY, p 94

Kirton J, Kokotsis E, Hudson A (2018) Controlling climate change through G7/8 G20 and UN leadership. In: Kirton J, Larionova M (eds) Accountability for effectiveness in global governance, 1 edn. Routledge, New York, NY, p 172

Larionova M, Kirton J (2020) Global Governance After the COVID-19 Crisis. Int Organ Res J 15(2):7-11. https://doi.org/10.17323/1996-7845-2020-02-01

Lawder D (2021) G20 recognizes carbon pricing as climate change tool for first time. https://www.reuters.com/business/sustainable-business/g20-recognizes-carbonpricing-climate-change-tool-first-time-2021-07-10/. Accessed 12 Jul 2021

Malpass D (2021) Building a green, resilient, and inclusive recovery. World Bank. https://www.worldbank.org/en/news/speech/2021/03/29/building-a-greenresilient-and-inclusive-recovery-speech-by-world-bank-group-presidentdavid-malpass. Accessed 1 Apr 2021

Martins M (2019) The BRICS commitment on climate change: process towards an effective approach in the path of sustainable development. In: Sequeira T, Reis L (eds) Climate change and global development. contributions to economics. Springer, Cham, pp. 175-187

McCourt DM (2016) Practice theory and relationalism as the new constructivism. Int Stud Quart 60(3):475-485

Morgan S (2020) Moscow cries foul over EU's planned carbon border tax. Euractiv News. https://digitallibrary.un.org/record/3880241?ln=en. Accessed 1 Aug 2020

O'Callaghan BJ, Murdock E (2021) Are we building back better? Evidence from 2020 and pathways for inclusive green recovery spending. United Nations Environment Programme. Available via https://wedocs.unep.org/bitstream/ handle/20.500.11822/35281/AWBBB.pdf. Accessed 1 Jun 2021

O'Callaghan BJ, Murdock E, Yau N (2021) Global recovery observatory-draft methodology document. https://recovery.smithschool.ox.ac.uk/global-recoveryobservatory-draft-methodology-document/. Accessed 31 May 2021

P4G Summit Seoul (2021) Seoul declaration. https://2021p4g-seoulsummit.kr/ notice/detail.do. Accessed 1 Jun 2021

Sending OJ (2002) Constitution, choice and change: problems with the 'logic of appropriateness' and its use in constructivist theory. Eur J Int Relat $8(4): 443-470$

Sending OJ, Pouliot V, Neumann IB (2015) Diplomacy and the making of world politics. Cambridge University Press, Cambridge

Tass (2021) Carbon border adjustment mechanism will harm Russian-EU trade, minister warns. https://tass.com/economy/1317313. Accessed 12 Aug 2021

Trownsell T, Escobari AQ, Shani G, Behera NC, Reddekop J, Tickner A (2019) Recrafting International Relations through Relationality. E-International Relations. https://www.e-ir.info/2019/01/08/recrafting-international-relationsthrough-relationality/. Accessed 1 Nov 2021

True J, Wiener A (2019) Everyone wants (a) peace: the dynamics of rhetoric and practice on 'Women, Peace and Security'. Int Aff 95(2):553-574

UK COP26 (2021a) Global finance ministers gather to discuss how public and private finance can lead the transition to a net-zero climate resilient world. https://ukcop26.org/global-finance-ministers-gather-to-discuss-how-publicand-private-finance-can-lead-the-transition-to-a-net-zero-climate-resilientworld/. Accessed 5 Nov 2021

UK COP26 (2021b) World leaders kickstart accelerated climate action at COP26. https://ukcop26.org/world-leaders-kick-start-accelerated-climate-action-atcop26/. Accessed 4 Nov 2021

UK COP26 (2021c) Political declaration on the just energy transition in South Africa. https://ukcop26.org/political-declaration-on-the-just-energy-transition-in-southafrica/. Accessed 3 Nov 2021

United Nations (2020) Climate change and COVID-19. https://digitallibrary.un.org/ record/3880241? $\ln =$ en. Accessed 1 May 2020

United Nations (2020) Climate change and COVID-19: UN urges nations to 'recover better'. https://www.un.org/en/un-coronavirus-communications-team/un-urgescountries-\%E2\%80\%98build-back-better\%E2\%80\%99. Accessed 21 Apr 2021

United Nations Environment Programme (2009) Global Green New Deal policy brief. https://wedocs.unep.org/bitstream/handle/20.500.11822/ 7903/A_Global_Green_New_Deal_Policy_Brief.pdf?sequence $=3 \&$ amp $\%$ 3BisAllowed $=$. Accessed 15 Apr 2021
United Nations General Assembly (2020) Comprehensive and coordinated response to the coronavirus disease (COVID-19) pandemic- GA Res 306. https://digitallibrary.un.org/record/3880241?ln=en. Accessed 21 Apr 2021

United States' Congress (2019) Recognising the duty of the Federal Government to create a Green New Deal. https://www.congress.gov/bill/116th-congress/ house-resolution/109/text. Accessed 11 Nov 2020

Viola LA (2019) The G20 through the lens of historical institutionalism. In Slaughter S (ed) The G20 and international relations theory. Edward Elgar Publishing, Cheltenham

Vivid Economics (2021) Greenness of stimulus index. https://www. vivideconomics.com/casestudy/greenness-for-stimulus-index/. Accessed 1 Aug 2021

White House (2021a) The build back better agenda. https://www.whitehouse.gov/ build-back-better/. Accessed 25 Aug 2021

White House (2021b) President Biden and G7 Leaders Launch Build Back Better World (B3W) Partnership. https://www.whitehouse.gov/briefing-room/ statements-releases/2021/06/12/fact-sheet-president-biden-and-g7-leaderslaunch-build-back-better-world-b3w-partnership/. Accessed 21 Jun 2021

World Economic Forum (2021) India's transition to a green economy presents a \$1 trillion opportunity. https://www.weforum.org/press/2021/11/india-s-transitionto-a-green-economy-presents-a-1-trillion-opportunity/. Accessed 10 Nov 2021

Xinhua (2021) Full text of BRICS Summit New Delhi Declaration. http:// www.news.cn/english/2021-09/10/c_1310178656.htm. Accessed 30 Sept 2021

\section{Acknowledgements}

The author is grateful for the work of the Global Recovery Observatory in their provision of data related to the greenness of the COVID-19 recovery.

\section{Competing interests}

The author declares no competing interests.

\section{Ethical approval}

This article does not contain any studies with human participants performed by any of the authors.

\section{Informed consent}

This article does not contain any studies with human participants performed by any of the authors.

\section{Additional information}

Supplementary information The online version contains supplementary material available at https://doi.org/10.1057/s41599-022-01046-2.

Correspondence and requests for materials should be addressed to Injy Johnstone.

Reprints and permission information is available at http://www.nature.com/reprints

Publisher's note Springer Nature remains neutral with regard to jurisdictional claims in published maps and institutional affiliations.

Open Access This article is licensed under a Creative Commons Attribution 4.0 International License, which permits use, sharing, adaptation, distribution and reproduction in any medium or format, as long as you give appropriate credit to the original author(s) and the source, provide a link to the Creative Commons license, and indicate if changes were made. The images or other third party material in this article are included in the article's Creative Commons license, unless indicated otherwise in a credit line to the material. If material is not included in the article's Creative Commons license and your intended use is not permitted by statutory regulation or exceeds the permitted use, you will need to obtain permission directly from the copyright holder. To view a copy of this license, visit http://creativecommons.org/ licenses/by/4.0/.

(C) The Author(s) 2022 